\title{
O PAPEL DA MOBILIDADE URBANA NOS SUPERPLANOS O Plano Urbanístico Básico de São Paulo (1968) e o Plano Doxiadis para o Estado da Guanabara (1965)
}

\author{
Maurício Feijó Cruz \\ Universidade de São Paulo - Faculdade de Arquitetura e Urbanismo \\ Orientador: Professora Doutora Regina Maria Prosperi Meyer \\ mauriciofeijo@usp.br
}

\section{RESUMO}

O presente trabalho tem como objetivo verificar o papel atribuído ao planejamento da mobilidade urbana no conjunto de proposições do Plano Urbanístico Básico do Município de São Paulo - PUB, de 1968, à luz da abordagem técnica integrada que caracterizou os chamados Superplanos realizados no Brasil nos anos 1960. Para tal, de acordo com a metodologia de historiografia cultural, são abordadas as práticas e representações relacionadas aos instrumentos de planejamento urbano utilizados tanto pelo PUB quanto pelo Plano Doxiadis para o Estado da Guanabara, de 1965, elaborado segundo os mesmos princípios de planejamento totalizante. O cruzamento desses documentos permite, de um lado, a verificação de pontos em comum e especificidades que caracterizam os princípios de planejamento difundidos no período, de modo a subsidiar reflexões sobre a abordagem da mobilidade urbana naquela etapa do processo de planejamento urbano no país e seus desdobramentos na prática atual da disciplina.

Palavras-chave: Planejamento Territorial Urbano; Mobilidade Urbana; Plano Urbanístico Básico do Município de São Paulo; Plano Doxiadis.

\begin{abstract}
This paper aims to verify the role attributed to urban mobility planning in the set of proposals of the São Paulo Basic Urban Plan - PUB (1968), in light of the integrated technical approach that characterized the so-called Super plans carried out in Brazil in the years 1960. To do so, according to the methodology of cultural historiography, this paper analyses the practices and representations related to the urban planning instruments used by both PUB and the Doxiadis Plan for the State of Guanabara (1965), elaborated according to the principles of totalizing planning. The cross-checking of these documents allows, on the one hand, the verification of common points and specificities that characterize the planning principles disseminated in the period, in order to subsidize reflections on the approach of urban mobility in that stage of the urban planning process in the country and its developments in the discipline's current practice.
\end{abstract}

Key-words: Urban Territorial Planning; Urban mobility; São Paulo Basic Urban Plan; Doxiadis Plan. 


\section{INTRODUÇÃO}

O presente trabalho tem como objetivo verificar o papel atribuído ao planejamento da mobilidade urbana no conjunto de proposições do Plano Urbanístico Básico do Município de São Paulo - PUB, de 1968, e do Plano Doxiadis para o Estado da Guanabara, de 1965, à luz da abordagem técnica integrada que caracterizou os chamados Superplanos realizados no Brasil nos anos 1960 (Villaça, 1999). Para tal, são analisadas as práticas e representações relacionadas aos instrumentos utilizados naquela etapa do processo de planejamento urbano no país e que apresentam desdobramentos na prática atual da disciplina.

O texto contextualiza os dois planos estudados à luz de uma breve história crítica do planejamento urbano no Brasil, e descreve as principais diretrizes e proposições do PUB e do Plano Doxiadis de maneira ampla e, especificamente, em relação ao papel da mobilidade urbana em suas elaborações, verificando posturas em comum e distanciamentos. Em suas considerações finais, procura-se analisar os modelos de abordagem de planejamento urbano desses documentos, compreendendo o quanto consolidaram enfoques que ainda caracterizam tal atividade em São Paulo, como a importação das mais modernas técnicas sem avaliação crítica e a ênfase propositiva de grandes estruturas sem compromisso com seus efeitos em escala local.

O artigo insere-se em um contexto de pesquisa que investiga os fundamentos teóricos utilizados na elaboração do planejamento da mobilidade urbana na metrópole de São Paulo a partir da década de 1960 por meio da análise das abordagens que encaminharam planos urbanos e políticas públicas para os deslocamentos na região, de modo a traçar um panorama sobre o papel atribuído à mobilidade como elemento de organização física e funcional do território. Objetiva-se, assim, verificar como cada abordagem articulou escalas de planejamento e projeto, ou seja, a relação entre as infraestruturas de mobilidade e o espaço urbano tendo em vista o potencial de organização da estrutura urbana que os sistemas de mobilidade têm no contexto atual da prática de planejamento em São Paulo.

\section{O ESTUDO DE PRÁTICAS E REPRESENTAÇÕES PARA A HISTÓRIA CULTURAL DA SOCIEDADE}

A presente pesquisa apoia-se nas abordagens de historiografia cultural realizadas na obra de Roger Chartier, que buscava "identificar o modo como em diferentes lugares e momentos uma determinada realidade social é construída, pensada, dada a ler" (Chartier, 1988:16-17). Dessa maneira, objetiva-se compreender os esquemas intelectuais e suas figuras que condicionam o sentido dado a cada realidade tornando-a inteligível, assim como os aspectos sociais, culturais e institucionais que determinam sua interpretação. Conforme aponta Miranda (1989:151), Chartier destaca que "todo o escrito obedece a categorias de pensamento e formas de apreensão do real - e que ao 'representarem' uma dada situação, também os textos criam realidades", colocando-se de maneira crítica à história total da segunda geração dos Annales, à história das mentalidades e à submissão da cultura a uma estrutura predeterminada de sociedade.

Chartier indica que todo objeto, sujeito e receptor cultural se desenvolvem em práticas e representações do modo de vida, e que a cultura configura-se como espaço de dominação pela universalização dos valores, sentimentos, práticas e significados de uma classe hegemônica, tendo em vista que não há interface entre cultura e sociedade, mas ambas estão imbricadas, como consciência e experiência. No presente artigo, as práticas e seus mecanismos de representação presentes nos processos de planejamento urbano no Brasil são destacados por seu papel simulador de adequação à modernidade dos planos elaborados,

[...] que faz tomar o logro pela verdade, que ostenta os signos visíveis como provas de uma realidade que não o é. Assim deturpada, a representação transforma-se em máquina de fabrico de respeito e de submissão [...]. (Chartier, 1988:22)

Nesse sentido, pode-se escrever a história do planejamento urbano desenvolvido pelo PUB-1968 por meio das práticas e representações nele presentes, como, por exemplo, o destaque à noção de 'planejamento integrado', o uso de ferramentas computacionais para simulação e avaliação de alternativas de redes de transporte, os desenhos esquemáticos de estruturação de todo o organismo urbano baseada em redes de infraestrutura rodoviária, e a contratação de planos junto a consultorias privadas internacionais, como será desenvolvido no item 4 deste artigo.

Do ponto de vista metodológico, a obra de Chartier (2009) sobre a história das práticas de escrita na Europa entre os séculos XVI e XVIII também contribui ao artigo pela crítica à delimitação territorial restrita de pesquisas, indicando a importância do cruzamento de fontes, o diálogo entre documentos e a conjugação de dados de outras monografias, o que levou no presente trabalho à busca do Plano Doxiadis para a Guanabara 
(Doxiadis Associates, 1965) como opção de ampliação da dimensão espacial da investigação, tanto pela análise do próprio documento produzido para a antiga capital federal quanto por monografias elaboradas sobre o assunto.

É nesse sentido que a pesquisa busca avançar, compreendendo as práticas e representações que se fazem presentes nos dois planos urbanos estudados em variadas dimensões (técnicas, políticas, sociais e ideológicas) e como produtos das transformações no pensamento e nas abordagens da realidade de metrópoles brasileiras.

\section{BREVE HISTÓRIA DO PLANEJAMENTO URBANO NO BRASIL}

Villaça (1999:180), ao se debruçar sobre a história e caracterização do campo do planejamento urbano no Brasil, afirma que "só podem ser consideradas da esfera do 'planejamento urbano' apenas aquelas ações do Estado sobre o urbano que tenham sido objeto de algum plano, por mais amplo que seja o conceito de plano". Assim, estudar os planos urbanos realizados no país seria, ao fazer a história desses objetos que se alteram ao longo do tempo, compreender como se configura a prática contemporânea do urbanismo e seu discurso dominante, entendendo seu processo de constituição e suas determinações.

A grande questão que se coloca ao se fazer a história do planejamento urbano é precisamente esta: o que deu origem ao plano diretor e ao tipo de planejamento urbano (na verdade discurso) hegemônico hoje no Brasil? O que, ao se transformar (ao mudar), deu origem a esse planejamento? (Villaça, 1999:176)

O autor indica 3 períodos do planejamento urbano no Brasil, distintos por seus princípios, discursos e resultados. O primeiro período (de 1875 a 1930), seria caracterizado por planos de melhoramentos e embelezamento orientados a implantar formas urbanas monumentais de exaltação à burguesia, inspirados nas intervenções que modificaram tecidos urbanos medievais na Europa (como as ações de Haussmann em Paris). Propunham, assim, transformações nos espaços urbanos coloniais brasileiros por meio da abertura de avenidas e bulevares que configuravam um novo conceito de infraestrutura para a circulação nas cidades, como no Plano de Pereira Passos para o Rio de Janeiro. O planejamento realizado e as ações implantadas tinham caráter elitizante, tratavam somente de trechos urbanos relevantes para as classes dominantes e reproduziam abertamente a hegemonia das mesmas sobre a cidade.

Já o segundo período, que se inicia na década de 1930, é "marcado pela ideologia do planejamento enquanto técnica de base científica, indispensável para a solução dos chamados 'problemas urbanos' " (Villaça, 1999:182). Destacam-se abordagens concebidas de maneira integrada e totalizante, resultando em proposições estruturantes baseadas em redes de transporte público e, principalmente, por grandes obras viárias. A percepção do distanciamento dos interesses das massas populares ao conteúdo dos planos e do discurso dominante torna-se então evidente, e as amplas propostas constituintes dos planos (que supostamente tratam de todo o território de forma equivalente) mostram-se totalmente alienadas da real possibilidade de sua implantação pela administração pública.

O terceiro período, que o autor indicava estar começando no final dos anos 1990 (momento da publicação da obra citada), configurava-se como reação ao anterior, marcado pela politização do planejamento - que viria a ser reforçado com a promulgação do Estatuto da Cidade em 2001 (Lei Federal 10.257) e seus mecanismos de participação popular para elaboração de planos diretores municipais e inclusão de princípios da função social da cidade. Com a publicação da Política Nacional de Mobilidade Urbana em 2012 (Lei Federal 12.587), verifica-se nova ênfase à necessidade de integração das políticas de desenvolvimento urbano e mobilidade urbana, incluindo o fomento a deslocamentos mais sustentáveis com priorização dos transportes coletivos e ativos.

Especificamente tratando do segundo período de planejamento urbano no país, Villaça sugere três subdivisões:

1. 1930-1965 - período do Urbanismo e do Plano Diretor: conjugava feições dos planos de embelezamento típicos do período anterior, mas destacavam o papel das infraestruturas urbanas, como as de saneamento e de transportes, organizadas segundo um discurso que incluía a abordagem da cidade em sua totalidade, mas cuja atenção estava na remodelação das áreas centrais tendo em vista suas oportunidades imobiliárias. Destacam-se no período o Plano Agache para o Rio de Janeiro e o Plano de Avenidas de Prestes Maia para São Paulo (ambos de 1930). 
2. 1965-1971 - Superplanos: auge do planejamento interdisciplinar e totalizante, articulando questões espaciais, sociais, institucionais e econômicas, integrando a cidade à sua região. O Plano Doxiadis para a Guanabara (1965) e o Plano Urbanístico Básico de São Paulo (PUB-1968) são os exemplos notáveis do período.

3. 1971-1992 - Planos sem mapa: documentos inócuos que enumeram objetivos, políticas e diretrizes bem intencionados e louváveis, sem discórdias nem conflitos por não conterem propostas concretas segundo a ideia de 'posterior detalhamento', como o Plano Diretor de Desenvolvimento Integrado de São Paulo (PDDI-1971) e o Plano Urbanístico Básico do Rio de Janeiro (PUB-Rio, 1977).

A seguir são apresentadas as principais características do período de planejamento urbano marcado pelos Superplanos, no qual se inserem os planos analisados no presente trabalho.

\section{OS SUPERPLANOS}

Desde os anos 1930, o urbanismo internacional era influenciado pelas ideias debatidas nos Congressos Internacionais da Arquitetura Moderna - CIAM, cujo discurso urbanístico havia sido consolidado na proposta da Cidade Funcional de 1933, rompendo com a estrutura tradicional das cidades existentes. Propunham-se tecidos urbanos abertos e funcionalmente hierarquizados, organizados em planos de larga escala com estratégias que, de um lado, focavam na criação de cidades novas (concretizadas em Brasília e Chandigarh), e de outro, tratavam da reordenação e reestruturação de áreas urbanas existentes.

Entretanto, após a Segunda Guerra Mundial, a necessidade de reconstrução das cidades europeias, o fenômeno da suburbanização norte-americana e o crescimento de metrópoles nos países menos desenvolvidos trouxeram à agenda dos urbanistas novos desafios que exigiriam o reconhecimento do espaço urbano e dos elementos das cidades existentes como locus de relações humanas, levando ao questionamento dos princípios da Carta de Atenas, em especial seu esquematismo e abstração. Essa polêmica marcou o debate dos CIAM dos anos 1950, e a partir disso novas direções foram elaboradas de modo a adequar a teoria da cidade moderna às necessidades colocadas pela realidade. Herdeiros dos esforços dos CIAM no segundo pós-guerra na criação de mecanismos pragmáticos e eficientes de planejamento, surgiram os princípios do Urban Design, desenvolvido pelo catalão Josep Lluís Sert nos Estados Unidos, e a Ekistics, criada pelo grego Constantinos Doxiadis ${ }^{1}$, ambos vinculados a experiências desses profissionais em cidades de países menos desenvolvidos (Rodríguez Sosa, 2008).

A circulação dessas novas práticas na América Latina nos anos 1950 e 1960 caracteriza-se tanto pela influência histórica das teorias dos CIAM na região quanto pela presença política crescente dos Estados Unidos e pela difusão da cultura norte-americana pelo continente (estilo de vida, padrões técnicos e construtivos, modelos de urbanização e consumo). Assim, a contratação de consultorias estrangeiras para a elaboração de planos no Brasil significava ter no país os experts internacionais do planejamento moderno, alinhados com o desenvolvimentismo (cujo modelo era o progresso do capitalismo norte-americano) e com o ideário de centralização do planejamento que vinha orientando os governos brasileiros (Rodríguez Sosa, 2008).

A incorporação dessas novas práticas no Brasil revela as contradições que se relacionam ao estágio de desenvolvimento do país então. Villaça (1999:211) indica que o período que antecede a emergência dos Superplanos no Brasil, de 1930 a 1965, "é marcado pela passagem do planejamento que era executado para o planejamento-discurso", tecnocrata e totalizante, porém alienado da capacidade técnica e financeira da administração pública local para implantar recomendações formuladas segundo modelos importados.

Ainda que destituídas de real vínculo com as realidades brasileiras, as novas práticas 'integradas' e tecnocratas adotadas para as questões urbanas apresentavam-se com plena legitimidade pois eram acompanhadas de diversas representações - compreendidas como algo que pode conferir uma visão de algo ausente. Por meio de símbolos reconhecidos por outros pelo significado compartilhado, era possível fornecer aparente competência às ações de planejamento. Assim, o planejamento urbano ganha destaque na ideologia disseminada acerca das possibilidades de resolução dos problemas sociais, reforçando a ideia de que somente abordagens integradas e construídas tecnicamente ofereceriam soluções eficazes para os problemas urbanos. Dessa maneira, a origem das dificuldades enfrentadas pelas populações urbanas estaria vinculada, exatamente, à falta da atividade de planejamento que leva ao crescimento caótico das cidades -

\footnotetext{
${ }^{1}$ Vale destacar que Doxiadis nunca foi membro oficial dos CIAM, ainda que pertencesse à geração de arquitetos contemporânea à circulação das ideias e postulados do Movimento Moderno (Rodríguez Sosa, 2008).
} 
ocultando-se o papel da própria organização social e do modelo de produção na configuração de problemas cuja solução nem as classes dominantes nem o Estado conseguiam enfrentar (Villaça, 1999).

Esse conjunto de ideias conforma as práticas sociais desse tempo e suas representações marcam a elaboração dos planos então produzidos, como extenso uso de dados estatísticos, projeções de crescimento, referências técnicas internacionais para proposição de densidades ideais, ferramentas computacionais para simulações eletrônicas de propostas, entre outras 'boas práticas' que, disseminadas nos meios profissionais e políticos, conferem legitimidade e autoridade ao planejamento realizado. A ideia de 'planejamento integrado' constrói-se, assim, compreendendo a cidade como objeto a ser trabalhado além de seus aspectos físicos por meio de obras de remodelação urbana elaborados pela engenharia ou pela arquitetura, mas sim como um organismo econômico e social, que funciona integrado à sua região sob um arcabouço político-institucional.

Essa reação às abordagens anteriores configura uma nova ideologia, a qual enseja novas determinações que constituem a realidade do processo de planejamento e que resultam nas práticas e representações verificadas nos documentos produzidos a partir de então. Mais do que isso, as determinações dessa ideologia explicam também as ausências de alguns temas ou práticas nesses planos, como o silêncio acerca das desigualdades sociais nas cidades ou a falta de diálogos com a sociedade por meio da participação popular. As contradições do modo de produção não se tornam objeto de reflexão, e os conflitos decorrentes da própria organização da sociedade, cristalizada em suas formas urbanas, são deixadas de lado. É nesse contexto que os dois Superplanos destacados são analisados a seguir.

\subsection{O papel central da mobilidade urbana no Plano Doxiadis para o Estado da Guanabara}

O chamado Plano Doxiadis - denominado "Guanabara, um plano para o desenvolvimento urbano" (Doxiadis Associates, 1965) foi elaborado para o então Estado da Guanabara² entre 1964 a 1965 pelo engenheiroarquiteto grego Constantinos A. Doxiadis (1913-1975) em seu escritório Doxiadis Associates, Consultants on Development and Ekistics (Resende, 2016), sob encomenda do governo de Carlos Lacerda (1960-1965), "marcando exemplarmente o início do período do Superplano tecnocrata que não é assumido pelo governante, apesar de encomendado por ele" (Villaça, 1999:211). O Plano já foi objeto de estudo de diversos autores, como Rezende (1982), Mello Júnior (1988), Farias Filho (2003) e Rodríguez Sosa (2008), sendo habitualmente considerado utópico, racionalista e focado em um modelo ideal pronto, resultante de conceitos e medidas internacionais e desvinculado da realidade nacional, que se torna mais importante que a própria cidade.

O Plano Doxiadis foi elaborado à luz dos preceitos da chamada Ekistics, conceito criado pelo próprio arquiteto grego a partir dos anos 1940 que consolidou suas ideias sobre os assentamentos humanos em todas suas escalas de complexidade, e foi muito difundido a partir de 1955.

Ekistics é a tradução de oikistikh, [...] que concerne à fundação de uma habitação, uma casa, uma cidade, um assentamento; [...]. Difundiu-se em inglês como Ekistics [...] como derivada da palavra grega EKOS ou habitat e do verbo EKO que significa assentar-se. Essa definição permitia identificar o assentamento humano com todas as escalas de desenvolvimento da vida do homem (casa, bairro, cidade e assim por diante), e dessa forma, incorporava no grande guarda-chuva da Ekistics tanto o planejamento regional, urbano e comunitário, como o desenho de uma casa, isto é, a arquitetura. (Rodríguez Sosa, 2008:164)

A definição de "assentamento humano" configura o ponto central da teoria Ekistics, relacionando o par content (o Homem) e container (elementos naturais e/ou artificiais feitos pelo homem). O estudo desses elementos e suas relações possibilitaria melhorar o equilíbrio entre o homem e seu assentamento, verificando a interconexão existente entre natureza, homem, sociedade, estruturas e redes. A Ekistics não se apresentava como nova teoria, mas sim uma nova ciência multidisciplinar que articularia conhecimentos da geografia, ecologia, economia, psicologia, antropologia, ciências sociais, políticas e culturais, estética, entre outras. Em outras palavras, podemos considera-la a síntese do "planejamento integrado".

O documento resultante do desenvolvimento do Plano apresenta-se grandioso: tem 375 páginas tamanho A3 e mais 118 páginas de apêndice (em sua versão original de 1965 escrita inteiramente em inglês ${ }^{3}$ ). Oferece

2 O Estado da Guanabara foi criado em 1960 após a mudança da capital federal para Brasília, correspondendo à área do atual município do Rio de Janeiro.

${ }^{3}$ Somente em 1967 o documento foi publicado pelo Estado da Guanabara em português. 
amplo diagnóstico do Estado da Guanabara em distintas escalas, destacando os problemas da concentração de empregos e atividades na Área Central do Rio de Janeiro, a saturação da capacidade do sistema viário existente, a falta de espaços para estacionamento, a ausência de um sistema de transporte público de massa e a operação descoordenada dos serviços ferroviários. Trabalhando com horizonte de planejamento de longos 35 anos (metas organizadas até o ano 2000, quando previa 8,4 milhões de habitantes na Guanabara ${ }^{4}$, mais 10 milhões no restante da área metropolitana ${ }^{5}$ ), o Plano inclui extensas diretrizes e propostas para os mais variados assuntos, indo do uso do solo ao fornecimento de energia elétrica, da provisão de cemitérios à implantação de rede de telefonia, além de recomendar a realização de novas pesquisas e planos de transporte.

A ideologia que relaciona os problemas urbanos à ausência de planejamento integrado aparece evidenciada nos textos do diagnóstico e das propostas que estruturam a implementação de ações setoriais coordenadas, sintetizados no sumário do Plano:

Conforme destacado ao longo deste estudo, existem muitos problemas na Guanabara hoje. A maior parte destes problemas está relacionada com a falta de um plano diretor e de um programa de regulação e coordenação do crescimento urbano, que é um pré-requisito necessário para a resolução dos problemas existentes e para a exclusão de problemas semelhantes no futuro" (Doxiadis Associates, 1965:X, tradução nossa).

Nesse contexto, é a estruturação viária do território do Estado da Guanabara com o objetivo de redistribuir o crescimento da região que constitui o ponto central das propostas do Plano Doxiadis, uma vez que seu diagnóstico considera o alto grau de centralização das principais funções urbanas e dos empregos no Centro do Rio de Janeiro (no 'Central Business District', no porto e em suas áreas industriais adjacentes) como a causa da saturação do seu sistema viário e das dinâmicas urbanas que desequilibram a cidade. Assim, o Plano se estrutura com a implantação de uma rede de vias expressas e expansão da rede de transporte público de massa que redistribuiriam os fluxos na cidade, em contraposição aos sistemas radiais então existentes, permitindo descentralização de atividades urbanas baseada na ampliação da acessibilidade de todo o território.

Ainda que o diagnóstico de mobilidade então disponível (referente a 1964) indicasse o predomínio do transporte público nos deslocamentos da população carioca - respondendo por $80 \%$ do total de viagens motorizadas realizadas na região, o Plano destaca como prioritários os investimentos na criação de novos eixos rodoviários, especialmente para contornar os morros que caracterizam o território, e no alargamento das artérias viárias existentes acompanhados de novos estacionamentos subterrâneos. Essa priorização se evidencia pela extensão das propostas de estruturação da rede de transportes que permitiria 15 milhões de viagens diárias em 2000: $402 \mathrm{~km}$ de freeways com total controle de acesso (projetadas para capacidade de 25.000 veículos/dia), $517 \mathrm{~km}$ de high standard expressways (capacidade de 12.500 veículos/dia) e major arteries (desenhadas para 10.000 veículos/dia), sendo que mais de um terço do total teria mais de 3 faixas por sentido, conforme a Tabela 1. Por outro lado, o Plano previa somente $80 \mathrm{~km}$ de linhas de metrô, restrito à área central, ao eixo de desenvolvimento leste-oeste proposto (descrito adiante) e a zonas mais adensadas, ainda que sujeito à elaboração de outros planos para sua implantação, além de estudos para sistemas de ônibus e hidroviário.

Tabela 1: Extensão de Freeways, Expressways e Major Arteries por número total de faixas.
\begin{tabular}{|ccccccc|} 
Classe de Highway \\
\hline \multicolumn{7}{|c|}{} \\
\hline Freeways & 4 faixas & 6 faixas & 8 faixas & 10 faixas & 12 faixas & total \\
\hline $\begin{array}{c}\text { Expressways ou } \\
\text { Major Arteries }\end{array}$ & 136 & 136 & 89 & 34 & 7 & 402 \\
\hline
\end{tabular}

Fonte: Tabulação própria a partir de DOXIADES ASSOCIATES, 1965.

Para se ter a dimensão do vulto da proposta viária, tais vias ocupariam cerca de $66 \mathrm{~km}^{2}$ de terras, correspondendo a 5,5\% da área do território de estudo (sem contar o sistema viário regular). A priorização se evidencia também nos recursos previstos para a implantação da rede viária: $\operatorname{Cr} \$ 1,15$ bilhão para construções, $\operatorname{Cr} \$ 2,3$ bilhões para desapropriações e mais $\operatorname{Cr} \$ 240$ milhões para melhorias e construção de novas vias

\footnotetext{
${ }^{4}$ O Censo IBGE 2000 contabilizou 6,32 milhões de habitantes na capital fluminense.

${ }^{5}$ A Região Metropolitana do Rio de Janeiro - RMRJ foi instituída somente em 1974, de modo que a utilização da nomenclatura "área metropolitana" representa aqui uma simplificação para denominar os municípios do entorno do Estado da Guanabara.
} 
coletoras e locais (total de $\mathrm{Cr} \$ 3,690$ bilhões). Já para o metrô, foram previstos cerca de $\mathrm{Cr} \$ 320$ milhões (menos de $9 \%$ do projetado para o sistema viário).

Além da função setorial de transportes, a extensa rede de transportes constituída por freeways e expressways tinha a função de estruturar os limites de bairros e comunidades, formando uma grelha de vias expressas que contornaria os morros da cidade e que delimitaria suas porções.

Dois eixos principais constituídos a partir do Centro da cidade - um para oeste (em direção à baía de Sepetiba) e outro ao norte (Av. Brasil) - estruturariam as comunidades em seu entorno e formariam centralidades lineares com as atividades então restritas à Área Central, sintetizando o papel central dos transportes na estruturação urbana proposta pelo Plano Doxiadis. O eixo leste-oeste (entre a Área Central, os bairros do Meier, Madureira, Bangu e Campo Grande até a então incipiente área industrial de Sepetiba) configura a centralidade linear que é a espinha dorsal do Plano, onde seriam implantadas as principais funções e atividades urbanas (cívicas, administrativas e institucionais, além de escritórios, serviços e comércios). A segunda zona, mais ao norte, abrigaria a expansão das funções nacionais e regionais da cidade, entre a Área Central (e o Porto), São Cristóvão e o norte do Estado. Ao longo da fronteira norte do Estado da Guanabara ficariam as indústrias de menor impacto, e na região de Sepetiba ficariam as áreas industriais pesadas. Além dessa distribuição de atividades, o Plano recomenda densidades máximas de 400 habitantes por hectare na Área Central e na Zona Sul, diminuindo gradualmente para o oeste e em direção à costa, com alguns pontos mais densos junto a áreas industriais, para abrigar seus trabalhadores.

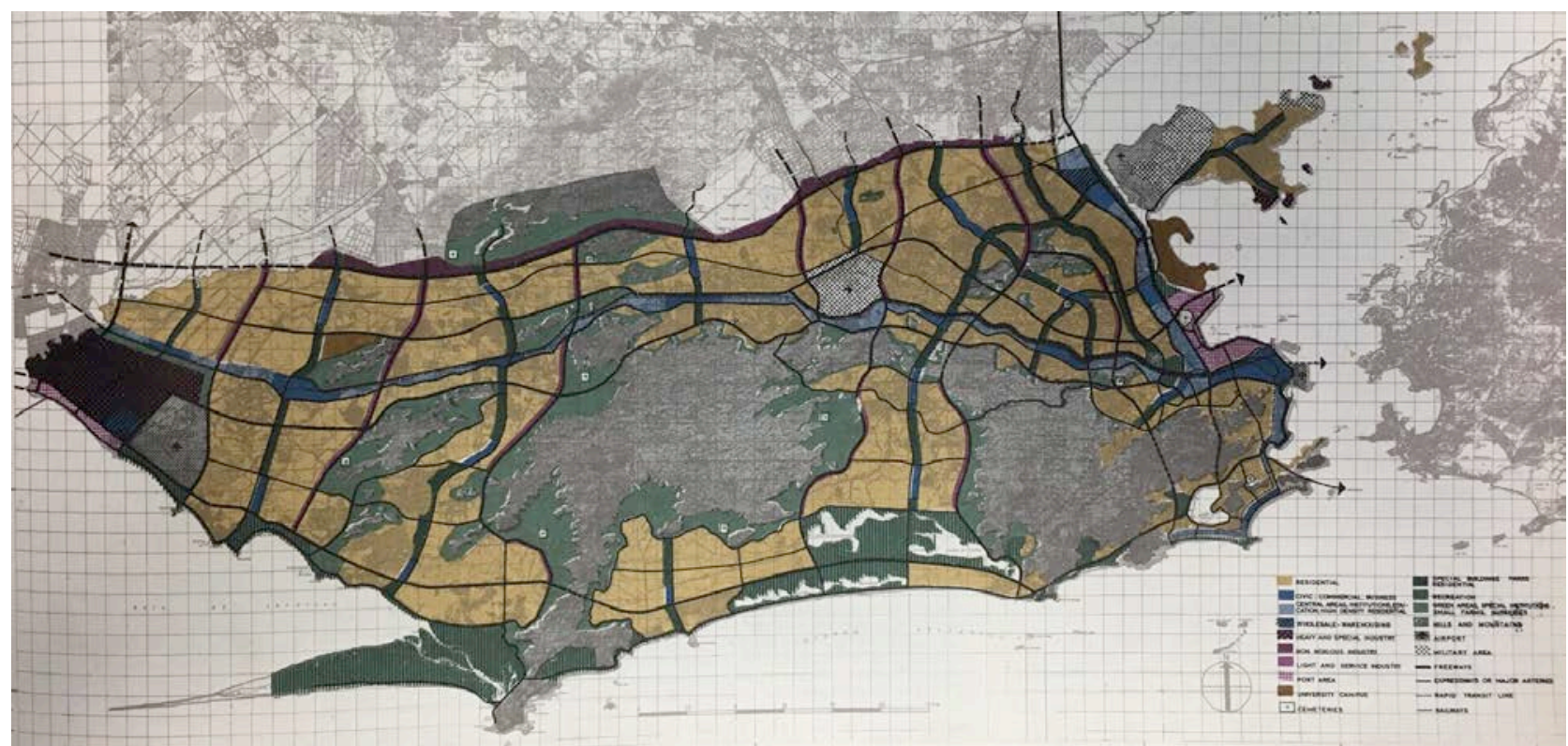

Figura 1: Esquema da grelha de vias expressas propostos pelo Plano Doxiadis para o Estado da Guanabara. Fonte: DOXIADES ASSOCIATES, 1965.

Dessa maneira, há uma intima relação entre o planejamento da mobilidade e o da ocupação do solo urbano, em um caso radical de 'planejamento integrado' da infraestrutura e do Zoneamento - ainda que com resultados potencialmente desarticuladores do tecido urbano devido às pesadas infraestruturas viárias previstas entre os limites dos bairros.

Levando em conta o papel de liderança que o transporte urbano desempenha no desenvolvimento urbano, pode-se afirmar que o planejamento adequado do transporte pode garantir o desenvolvimento adequado da cidade. Por outro lado, o bom planejamento urbano pode contribuir muito para solucionar adequadamente os problemas de transporte urbano existentes ou para evitar a criação de novos. (Doxiadis Associates, 1965:269, tradução nossa)

O Plano Doxiadis utilizou metodologia de planejamento de transportes com modelos matemáticos para testes e avaliação de alternativas em computadores eletrônicos, mas não dispunha de uma pesquisa ampla que fornecesse dados primários abrangentes. Isso reduziu tanto a compreensão das características das viagens de então quanto o cálculo do prognóstico futuro da geração e distribuição dos deslocamentos com técnicas matemáticas. Foram então feitas pesquisas menores, como velocidade dos deslocamentos, tempo de viagens 
e contagens de volumes de tráfego nas principais vias, além de cálculos de projeção de posse de automóveis de acordo com a evolução da renda (previa-se 1.500.000 veículos em 2000, quase 8 vezes o número de então). Por outro lado, o Plano logrou relativo detalhamento de propostas de traçado do sistema viário, com inclusão de mapas 1:50.000 em que as novas vias foram articuladas ao sistema viário existente e ao relevo.

Algumas das vias propostas pelo Plano Doxiadis foram executadas na cidade, como a conexão entre os bairros de Laranjeiras e Santo Cristo (Av. Trinta e Um de Março e Túnel Santa Bárbara, 1963), a Linha Vermelha, entre São Cristóvão e São João de Meriti (Via Expressa Presidente João Goulart, 1992), e a Linha Amarela (Avenida Governador Carlos Lacerda, 1997), entre Jacarepaguá e a Ilha do Fundão. As vias que abrigam os recentes corredores de Bus Rapid Transit - BRT TransCarioca (2014) e TransOlímpica (2016) também seguem traçados previstos pelo Plano para ligação da Penha ao Recreio dos Bandeirantes.

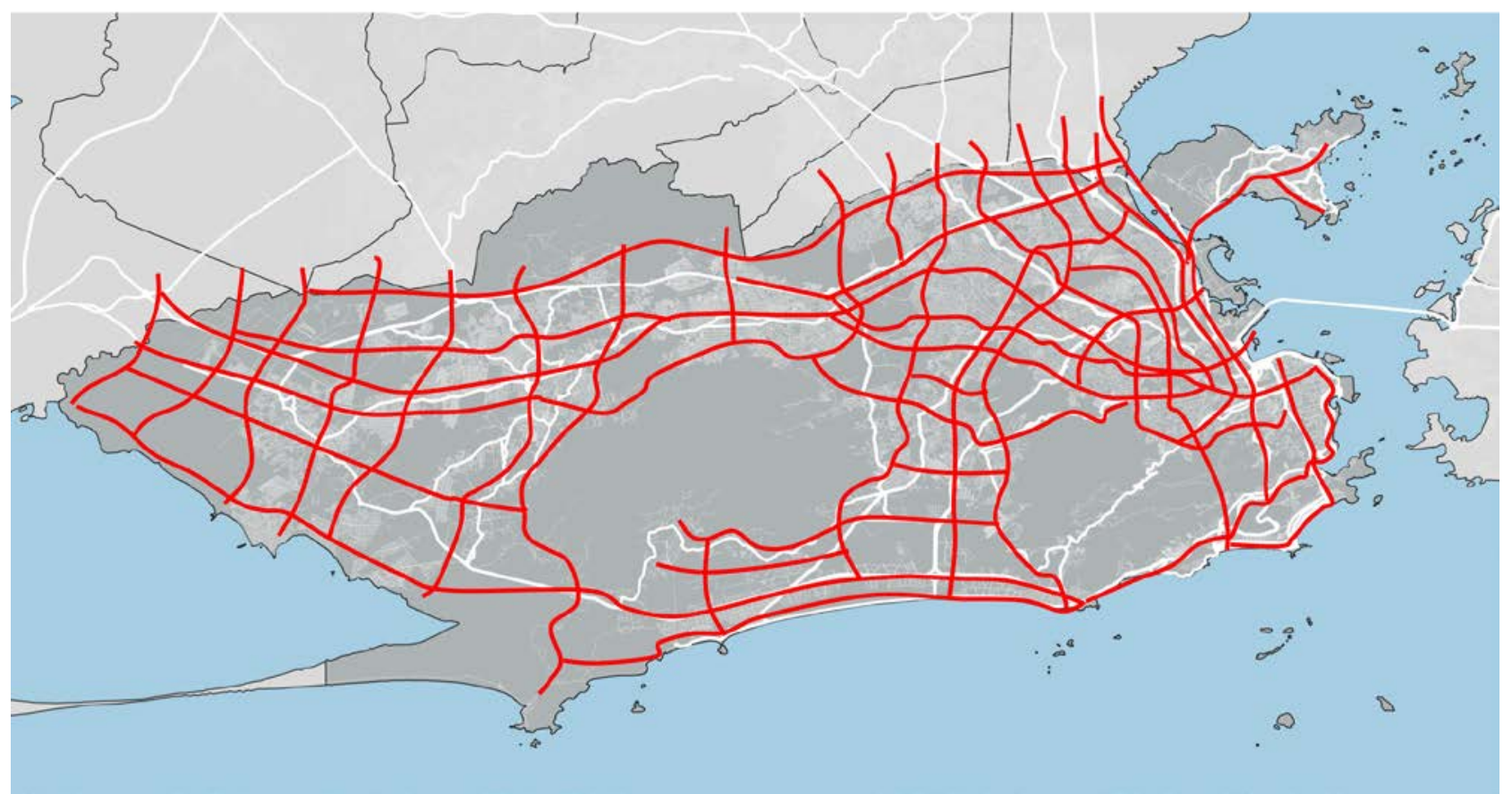

Figura 2: Comparação entre o esquema da grelha de vias expressas propostos pelo Plano Doxiadis para o Estado da Guanabara a atual estruturação da malha viária do Rio de Janeiro.

Fonte: Elaboração própria a partir de DOXIADES ASSOCIATES (1965).

\subsection{A abordagem da Mobilidade Urbana no PUB}

Contratado pela gestão do Prefeito José Vicente de Faria Lima junto ao consórcio formado pelas empresas brasileiras Asplan - Assessoria em Planejamento, e Montreal Empreendimentos, e as norte-americanas Leo A. Daly Company e Wilbur Smith and Associates (com participação das também americanas Real Estate Research Co. e Hazen \& Sawyer), o Plano Urbanístico Básico de São Paulo - PUB foi desenvolvido ao longo do ano de 1968 tornando-se o documento emblemático produzido na capital paulista no período caracterizado pelo planejamento integrado. Alinhado à abordagem totalizante multidisciplinar, o PUB congregou profissionais de planejamento urbano, educação, engenharia, legislação e transportes, entre outros, que produziram um Plano de seis volumes com mais de três mil páginas de pesquisas, diagnósticos detalhados, dados estatísticos, mapas, gráficos e projeções abrangendo todos os aspectos da vida urbana (Feldman, 2005), divididas em seis volumes: Desenvolvimento físico e socioeconômico, Desenvolvimento Urbano, Desenvolvimento Social, Circulação e Transportes, Serviços Urbanos e Administração Pública.

Concebido como o Plano Diretor que o município ainda não tinha (Somekh \& Campos Neto, 2002), utilizou extensa base de informações e pesquisas associadas a técnicas de computação e modelos matemáticos para elaborar e testar amplas recomendações e diretrizes seguindo os moldes dos planos e legislações norteamericanas (Grillo, 2013). Colocava-se, assim, com o objetivo de ir além da estruturação viária que caracterizava os grandes planos anteriores (o Estudo de Avenidas de Prestes Maia, de 1930, e o Relatório Moses, de 1950), com propostas para a capital com horizonte de planejamento no ano de 1990 (no qual se 
previa uma população de 10 a 13 milhões de pessoas ${ }^{6}$ ) nas áreas de educação, habitação, cultura, circulação e transportes, serviços e equipamentos públicos e estímulo à atividade econômica.

O PUB conjuga a proposta de expansão viária às medidas dos demais eixos propositivos que, integrados, contribuiriam para a melhoria da qualidade de vida da população, enfrentando inclusive o crescimento acelerado da cidade naquele momento e a defasagem da oferta de serviços públicos resultante desse processo. Feldman (2005) indica que o PUB foi o primeiro plano desenvolvido na capital paulista que incorporou uma legislação de zoneamento com o objetivo de disciplinar o desenvolvimento da cidade, acompanhado de diretrizes de parcelamento do solo, permissão de instalação de atividades e parâmetros urbanísticos, ainda que sem delimitação de zonas, mas com detalhamentos para zonas-tipo. Assim, o plano propôs uma estrutura urbana baseada em altas densidades no Centro e bolsões residenciais de baixa e média densidades nos bairros, articulados por uma malha viária de $815 \mathrm{~km}$ de vias expressas (que receberiam cerca de 6,8 milhões de viagens diárias de carro em 1990). O PUB propõe ainda um "sistema de planejamento para a administração municipal abrangendo medidas legais, administrativas e financeiras" (Grillo, 2013:72), e recomenda a formação de órgãos metropolitanos para implantação e gerenciamento dos sistemas de transportes coletivos e da rede de vias expressas.

O Volume IV do PUB, específico do tema Circulação e Transportes, foi desenvolvido a partir dos dados obtidos na primeira grande pesquisa de transportes realizada na região, a Pesquisa Origem-Destino conduzida em 1967 para o planejamento do Metrô da capital, e que encaminharam as projeções de viagens para o ano de 1990 alinhadas às práticas e técnicas de planejamento que conferiam autoridade ao PUB:

No desenvolvimento das principais recomendações para o transporte, foram usados, para a projeção das viagens futuras, os mais modernos métodos de computação, permitindo tirar conclusões lógicas sobre a extensão e a configuração básica de um sistema de transporte funcional. (São Paulo, 1969:250-251).

É constantemente reforçado no referido Volume o compromisso em proporcionar capacidade de vias e equipamentos de transporte coletivo que atendam adequadamente à demanda, de modo que o planejamento das alternativas de transporte foi relacionado às densidades de população e emprego existentes ou previstas para cada região da cidade. Trata-se, como no exemplo do Plano Doxiadis, de uma radical integração conceitual entre as políticas de uso do solo e transporte.

Os sistemas de transporte não podem ser considerados isoladamente, mas precisam ser relacionados ao uso da área a que servem. As vias e os equipamentos de transporte coletivo servem às atividades sociais e econômicas da população e, assim, existe estreita relação entre os sistemas de transporte e a estrutura urbana. $\mathrm{Na}$ medida em que cada alternativa de transporte é baseada em uma hipótese específica de uso do solo, a própria estrutura urbana é influenciada pelas possibilidades técnicas de transporte. (São Paulo, 1969:178)

Na zona central e nas concentrações comerciais o transporte coletivo era considerado "mais desejável", estando nelas, portanto, as propostas de linhas de Metrô e trem. Como consequência, haveria desencorajamento da mobilidade motorizada individual nesses trechos da cidade, inclusive com proibição do estacionamento nas ruas, cobrança de altas taxas em lotes e garagens, Congestion charges, taxação ou aumento dos impostos sobre a gasolina e sobre o licenciamento de carros. O PUB indica que as "áreas residenciais de densidade média para baixo são servidas pelo transporte particular, complementado pelo serviço de ônibus para aqueles que não possuem carro" (São Paulo, 1969:178, grifo nosso), o que talvez revele uma contradição conceitual sobre a que (ou quem) se destina o transporte coletivo.

Para elaborar as alternativas de transporte, foram considerados três modelos de desenvolvimento urbano que variavam quanto à intensidade do uso do solo projetado pelas características de zoneamento proposto e que, portanto, determinavam os tipos de sistemas de transporte adequados a cada área da cidade. Assim, quanto mais alta a densidade populacional do conjunto de cada modelo, maior o tamanho relativo do sistema de Metrô frente aos sistemas de ônibus e transporte particular. Se as centralidades tivessem um desenvolvimento linear, corredores de transporte coletivo de alta capacidade atenderiam a demanda de viagens, assim como nos subcentros de alta densidade; por outro lado, se houvesse desenvolvimento de muitos núcleos dispersos, o Metrô daria lugar a vias expressas e serviços de ônibus.

\footnotetext{
${ }^{6}$ No Censo IBGE 1991, o Município de São Paulo contava com 9.626.894 habitantes.
} 
De qualquer forma, a estrutura viária básica proposta, que variava em extensão ou capacidade em razão dos três modelos de desenvolvimento urbano, configurava uma grelha (com eixos norte-sul e leste-oeste) de vias expressas que organizava múltiplas centralidades (Figura 1). Tal esquema distinguiu-se das propostas e intervenções radioconcêntricas advindas de planos anteriores, mas não alterou o modelo de estruturação viária adotado na região, baseado em avenidas radiais e perimetrais, conforme a Figura 2.

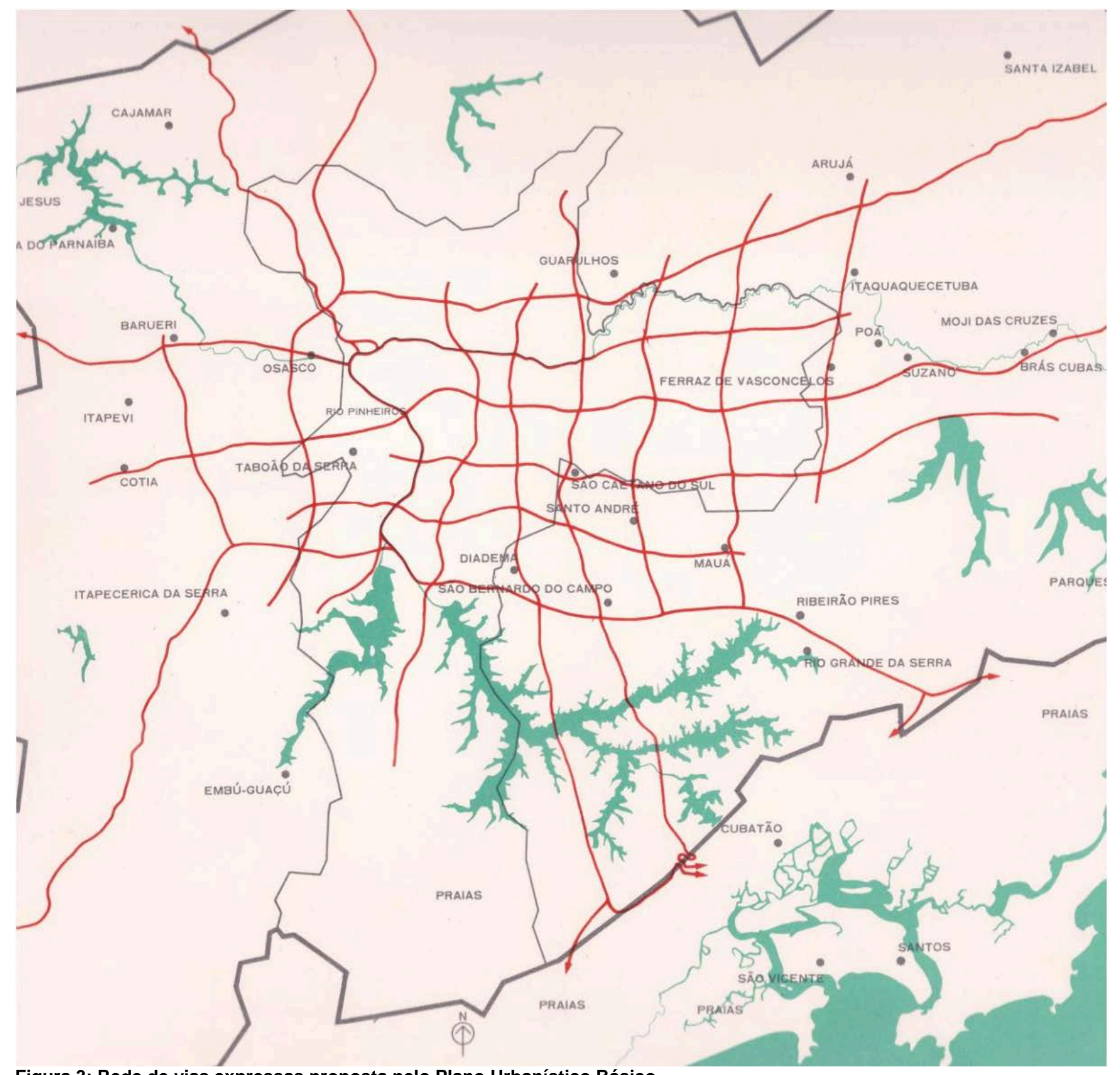

Figura 3: Rede de vias expressas proposta pelo Plano Urbanístico Básico. Fonte: SÃO PAULO, 1969. 


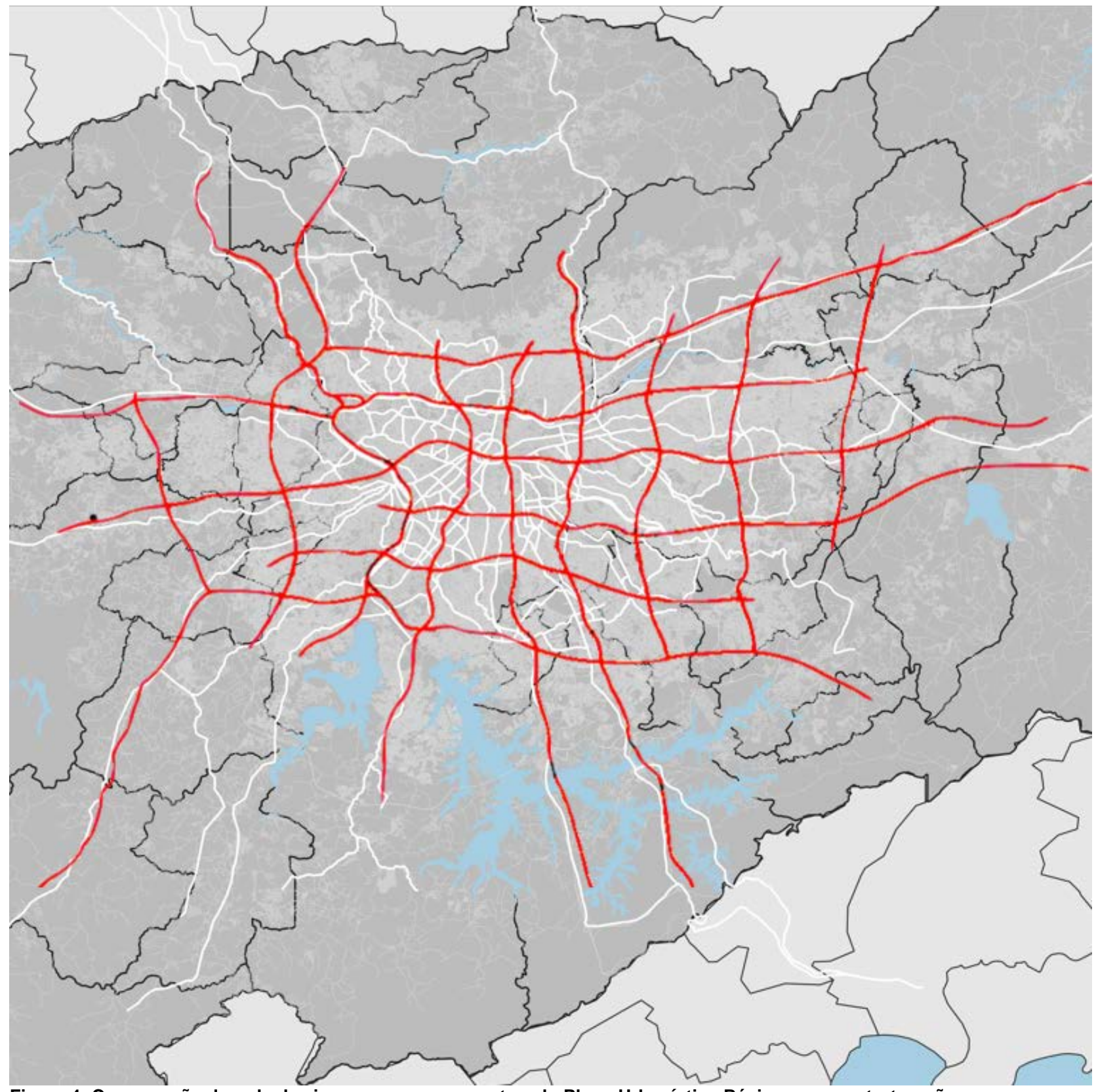

Figura 4: Comparação da rede de vias expressas proposta pelo Plano Urbanístico Básico com a estruturação radioconcêntrica da malha viária regional atual.

Fonte: Elaboração própria a partir de SÃO PAULO (1969).

Para cada um dos dois modelos iniciais de uso do solo foram desenvolvidas duas alternativas de redes de transportes: um sistema orientado para o transporte individual, que compreendia extensa rede de vias expressas combinada a um sistema de trânsito rápido ${ }^{7}$ (constituído pelas linhas férreas existentes e de uma pequena rede de Metrô); e um sistema orientado para o transporte coletivo, que contava com uma menor extensão de vias expressas complementada por sistema relativamente extenso de Metrô e estradas de ferro. Em todos os casos os sistemas estruturais deveriam ser complementados por vias arteriais, linhas de ônibus, dutos, terminais de carga e de passageiros e aeroportos.

Todavia, os volumes de tráfego resultantes dos testes realizados nesses dois primeiros modelos de uso do solo não se adequavam à oferta dos sistemas de transportes avaliados, mesmo com as duas diferenciações realizadas na orientação de sistemas. No Modelo 1 de uso do solo, o sistema de transporte coletivo e as vias expressas mostraram-se extremamente sobrecarregados, enquanto no Modelo 2 os volumes nas vias expressas superariam suas capacidades e diversos trechos do sistema do Metrô teriam demandas muito

${ }^{7}$ O termo 'trânsito rápido' era uma tradução inusitada (e com potencial de interpretação equivocada) do inglês 'rapid transit', termo que trata de transporte coletivo de massa sobre trilhos em vias segregadas, e não trânsito de veículos. 
abaixo de sua capacidade. A partir disso foi elaborado um terceiro Modelo, acompanhado de nova alternativa de sistema de transportes, que resultou em volumes de transporte coletivo um pouco mais altos e volumes viários muito mais baixos, quando comparados com o Modelo 2 .

O resultado dessas simulações é apresentado no Plano com dados sobre produção de viagens, tempo médio de viagem, distribuição de frequências dos tempos de viagem, desenho de curvas isócronas, entre outros parâmetros típicos das práticas de planejamento de transporte. Entretanto, mesmo com as alterações feitas na modelagem de uso do solo ou na ênfase no transporte individual e coletivo, o Plano indica que nem mesmo a terceira proposta levaria a um cenário futuro equilibrado, o que pode sugerir que todo o processo tivesse maior compromisso com a representação do uso de uma técnica mais do que, de fato, de utilização de uma ferramenta que conduz a prática do desenvolvimento de propostas:

\begin{abstract}
"Quando os volumes de tráfego foram comparados com as capacidades, observaram-se vários graus de sobrecarga em todas as alternativas e uma análise minuciosa revelou que os mesmos se deviam a grandes concentrações de população, concentrações de emprego industrial, desequilíbrio entre a população e o emprego em várias áreas, e, acima de tudo, o volume enorme de pessoas, empregos e atividades socioeconômicas aglomerado em uma área relativamente pequena" (São Paulo, 1969:204-205).
\end{abstract}

Tratava-se do mesmo problema verificado pelo Plano Doxiadis na Guanabara, ou seja, o desequilíbrio na distribuição de população e empregos. O PUB não explicita a extensão dos graus de sobrecarga verificados, mas indica que se concentram na área central do município, o que condicionaria o limite da implantação de soluções tanto em relação à ampliação do sistema viário quanto da participação do transporte coletivo, deixando para a população a função de buscar uma redistribuição mais equilibrada:

"[...] uma vez que na parte central do sistema viário a malha prevista representa o máximo de vias que podem ser construídas, o problema das sobrecargas não será resolvido simplesmente mediante a recomendação de mais vias. Nem seria realístico transferir para os transportes coletivos um volume substancial das viagens por carro, visto que $59 \%$ de todas as viagens carregadas naquele sistema já representam uma percentagem elevada. [...] Entretanto, diante dos congestionamentos resultantes, as pessoas serão motivadas a escolher melhores locais de moradia, trabalho, compras e negócios. Isso poderá resultar num menor número de habitantes e de proprietários de carros do que os projetados nas áreas sobrecarregadas. [...] Isso deverá espalhar os volumes de tráfego de maneira mais uniforme, em toda a extensão do sistema, e resultará em fluxo geral mais livre do que aquele indicado pelos volumes de tráfego resultantes dos testes." (São Paulo, 1969:231)

Ora, se fora preconizado que o planejamento das alternativas de transporte do Plano seria relacionado às densidades de população e emprego existentes ou previstas, parece que o planejamento integrado encontrou aí um limite de empregabilidade - seja pela opção em não calibrar a distribuição das atividades urbanas na modelagem urbanística (ainda que o PUB recomende uma metrópole descentralizada e polinucleada), ou pela crença de que não poderia haver incremento na capacidade da rede de transporte coletivo para atender as viagens resultantes do modelo de uso do solo (acompanhado na insistência no predomínio do sistema de vias expressas).

Outro dos aspectos relevantes da proposta de transportes do PUB é a omissão sobre os traçados pormenorizados tanto das novas linhas de metrô sugeridas e localização de terminais, quanto das vias expressas ou arteriais, que deveriam ser detalhados posteriormente de acordo com a disponibilidade de espaços. Tendo em vista a necessidade de amplas faixas de domínio para viabilizar a implantação de vias segundo preceitos geométricos rígidos de implantação recomendados (vias em trincheiras, com rampas de acesso controlado ao sistema viário geral, altas velocidades de projeto, cruzamentos em desnível), é curioso perceber que o plano, ao indicar tantas especificidades, tenha proposto tamanha extensão de vias expressas incompatíveis com o próprio relevo do município. Tal geometria poderia ser implantada, sem investimentos vultosos em desapropriações e movimentos de terra, somente nos vales mais encaixados, com grande aprofundamento do talvegue, o que pode indicar o uso de soluções desvinculadas da realidade local, mas alinhadas a soluções e preceitos técnicos ideais. 
As tabelas a seguir auxiliam a compreender as características e diferenças de cada alternativa testada, sendo a Tabela 2 somente para o Município de São Paulo e a Tabela 3 para o conjunto da Grande São Paulo. Destaca-se, de antemão, que as maiores variações nas propostas referem-se à extensão da rede de transporte coletivo que, mesmo ampliada com o desenvolvimento dos testes, permanece bem menor que o sistema de vias expressas planejados desde o início do trabalho.

Tabela 2: Componentes das alternativas dos sistemas de transporte para o Município de São Paulo (1990)

\begin{tabular}{|c|c|c|c|c|c|}
\hline \multirow{2}{*}{$\begin{array}{c}\text { COMPONENTES DO } \\
\text { SISTEMA }\end{array}$} & \multicolumn{2}{|c|}{ MODELO 1 DO USO DO SOLO } & \multicolumn{2}{|c|}{ MODELO 2 DO USO DO SOLO } & \multirow{2}{*}{$\begin{array}{c}\text { MODELO } 3 \text { DO } \\
\text { USO DO SOLO } \\
\text { Alternativa E }\end{array}$} \\
\hline & Alternativa A (1) & Alternativa B (2) & Alternativa C (1) & Alternativa D (2) & \\
\hline \multicolumn{6}{|l|}{ RODOVIAS } \\
\hline Vias expressas & 329 km & 268 km & 329 km & 315 km & 369 km \\
\hline $\begin{array}{c}\text { Interseções entre vias } \\
\text { expressas }\end{array}$ & 33 & 24 & 33 & 29 & 34 \\
\hline $\begin{array}{c}\text { Interseções via expressa - } \\
\text { via arterial }\end{array}$ & 110 & 92 & 107 & 76 & 113 \\
\hline \multicolumn{6}{|l|}{ FERROVIAS (3) } \\
\hline Linhas de passageiros & 161 km & 186 km & 150 km & 141 km & $150 \mathrm{~km}$ \\
\hline $\mathrm{N}^{\circ}$ de estações & 54 & 60 & 37 & 41 & 37 \\
\hline $\begin{array}{c}\text { Distância média entre as } \\
\text { estações }\end{array}$ & $3,01 \mathrm{~km}$ & $3,01 \mathrm{~km}$ & $3,72 \mathrm{~km}$ & $2,93 \mathrm{~km}$ & $3,72 \mathrm{~km}$ \\
\hline \multicolumn{6}{|l|}{ METRÔ } \\
\hline Linhas locais & 66 km & 161 km & 206 km & 223 km & 210 km \\
\hline Linhas expressas & - & - & - & $69 \mathrm{~km}$ & - \\
\hline $\mathrm{N}^{\circ}$ total de estações & 68 & 131 & 124 & 125 & 124 \\
\hline $\mathrm{N}^{\circ}$ de estações expressas & - & - & - & 25 & - \\
\hline $\begin{array}{c}\text { Distância média entre as } \\
\text { estações }\end{array}$ & $0,89 \mathrm{~km}$ & $1,11 \mathrm{~km}$ & $1,47 \mathrm{~km}$ & $1,67 \mathrm{~km}$ & $1,43 \mathrm{~km}$ \\
\hline
\end{tabular}

Fonte: SÃO PAULO, 1969:192.

(1) Plano orientado para o transporte individual; (2) Plano orientado para o transporte coletivo; (3) Utilizado para transporte suburbano. 
Tabela 3: Componentes das alternativas dos sistemas de transporte para a Grande São Paulo: 'Área Urbana de Planejamento' e 'Restante da Área Estudada' (1990)

\begin{tabular}{|c|c|c|c|c|c|}
\hline \multirow{2}{*}{$\begin{array}{l}\text { COMPONENTES DO } \\
\text { SISTEMA }\end{array}$} & \multicolumn{2}{|c|}{ MODELO 1 DO USO DO SOLO } & \multicolumn{2}{|c|}{ MODELO 2 DO USO DO SOLO } & \multirow{2}{*}{$\begin{array}{l}\text { MODELO } 3 \text { DO } \\
\text { USO DO SOLO } \\
\text { Alternativa E }\end{array}$} \\
\hline & Alternativa A (1) & Alternativa B (2) & Alternativa C (1) & Alternativa D (2) & \\
\hline \multicolumn{6}{|c|}{ ÁREA URBANA DE PLANEJAMENTO } \\
\hline \multicolumn{6}{|l|}{ RODOVIAS } \\
\hline Vias expressas & $445 \mathrm{~km}$ & 350 km & $443 \mathrm{~km}$ & $404 \mathrm{~km}$ & $448 \mathrm{~km}$ \\
\hline $\begin{array}{l}\text { Interseções entre vias } \\
\text { expressas }\end{array}$ & 44 & 31 & 44 & 38 & 46 \\
\hline $\begin{array}{c}\text { Interseções via expressa - } \\
\text { via arterial }\end{array}$ & 143 & 110 & 140 & 99 & 146 \\
\hline \multicolumn{6}{|l|}{ FERROVIAS (3) } \\
\hline Linhas de passageiros & 146 km & $215 \mathrm{~km}$ & $147 \mathrm{~km}$ & $182 \mathrm{~km}$ & $147 \mathrm{~km}$ \\
\hline $\mathrm{N}^{\circ}$ de estações & 56 & 66 & 39 & 48 & 39 \\
\hline $\begin{array}{c}\text { Distância média entre as } \\
\text { estações }\end{array}$ & $2,5 \mathrm{~km}$ & $3,02 \mathrm{~km}$ & $3,5 \mathrm{~km}$ & $3,44 \mathrm{~km}$ & $3,5 \mathrm{~km}$ \\
\hline \multicolumn{6}{|l|}{ METRÔ } \\
\hline Linhas locais & $66 \mathrm{~km}$ & 189 km & $254 \mathrm{~km}$ & $274 \mathrm{~km}$ & $250 \mathrm{~km}$ \\
\hline Linhas expressas & - & - & - & $69 \mathrm{~km}$ & - \\
\hline $\mathrm{N}^{\circ}$ total de estações & 68 & 154 & 143 & 144 & 139 \\
\hline $\mathrm{N}^{\circ}$ de estações expressas & - & - & - & 25 & - \\
\hline $\begin{array}{c}\text { Distância média entre as } \\
\text { estações }\end{array}$ & $0,89 \mathrm{~km}$ & $1,11 \mathrm{~km}$ & $1,52 \mathrm{~km}$ & $1,79 \mathrm{~km}$ & $1,54 \mathrm{~km}$ \\
\hline \multicolumn{6}{|c|}{ RESTANTE DA ÁREA ESTUDADA } \\
\hline \multicolumn{6}{|l|}{ RODOVIAS } \\
\hline Vias expressas & 316 km & $286 \mathrm{~km}$ & 304 km & $259 \mathrm{~km}$ & $424 \mathrm{~km}$ \\
\hline $\begin{array}{l}\text { Interseções entre vias } \\
\text { expressas }\end{array}$ & 7 & 8 & 7 & 8 & 9 \\
\hline $\begin{array}{c}\text { Interseções via expressa - } \\
\text { via arterial }\end{array}$ & 46 & 46 & 49 & 37 & 60 \\
\hline \multicolumn{6}{|l|}{ FERROVIAS (3) } \\
\hline Linhas de passageiros & $150 \mathrm{~km}$ & $178 \mathrm{~km}$ & $206 \mathrm{~km}$ & 249 km (4) & $206 \mathrm{~km}$ \\
\hline $\mathrm{N}^{\circ}$ de estações & 51 & 53 & 44 & $46(4)$ & 44 \\
\hline $\begin{array}{c}\text { Distância média entre as } \\
\text { estações }\end{array}$ & $3,09 \mathrm{~km}$ & $3,45 \mathrm{~km}$ & $4,93 \mathrm{~km}$ & $4,99(4)$ & 4,93 \\
\hline
\end{tabular}

Fonte: SÃO PAULO, 1969:189-192.

(1) Plano orientado para o transporte individual; (2) Plano orientado para o transporte coletivo; (3) Utilizado para transporte suburbano

(3) Inclui a linha de Metrô para Mogi das Cruzes (20 km de linhas e 5 estações fora da área urbana de planejamento).

\section{SÍNTESE DO PAPEL DA MOBILIDADE URBANA NOS SUPERPLANOS}

O cruzamento dos dois Superplanos permite, de um lado, a verificação de pontos em comum que caracterizam os princípios de planejamento difundidos no período, e, por outro, revela as especificidades que distinguem cada plano. A compreensão das práticas e representações presentes nos dois documentos estudados como produtos das transformações no pensamento e nas abordagens da realidade de metrópoles brasileiras revela a origem das características atuais da atividade de planejamento urbano no Brasil e subsidia o olhar crítico para esse campo profissional. 
Em ambos os planos é claro o destaque à noção de 'planejamento integrado' que constitui seus escopos de atuação, marcados pelo amplo panorama de diversos temas urbanos articulados para abarcar a totalidade das questões setoriais de cada metrópole, inclusive de suas infraestruturas para serviços públicos (como telecomunicações, saúde, educação e drenagem, entre outros), desenvolvimento da administração pública e até desenhos de seções-tipo de vias. A profusão de detalhamentos seletivos revela-se, entretanto, descolada da realidade, uma vez que não foram acompanhados de uma comparação entre o montante de investimentos necessários para a implantação das propostas e a capacidade de endividamento ou alocação de recursos orçamentários dos governos locais - ainda que isso possa ter sido motivado pela crença no próspero crescimento econômico futuro no contexto do regime militar em que esses planos foram desenvolvidos.

Tanto o PUB quanto o Plano Doxiadis focam na implantação de uma rede de vias expressas que reorganiza os fluxos na cidade, em contraposição aos sistemas radiais então existentes, apresentados por desenhos esquemáticos de estruturação de todo o organismo urbano, diferindo entre si quanto a escalas maiores ou menores de detalhamento de inserção urbana. Se no PUB são recomendadas vias expressas isoladas em trincheiras, mascarando seu potencial de segregação urbana (ainda que pouco viáveis dado o relevo do sítio urbano paulistano e as vultosas desapropriações necessárias), no Doxiadis elas são assumidas como elementos de separação entre comunidades, com maior possibilidade física de implantação pois muitas delas eram previstas em áreas ainda não urbanizadas, especialmente na Zona Oeste da Guanabara. Em nenhum dos planos há ponderações críticas sobre os vultosos custos envolvidos na execução da rede de vias expressas, especialmente quando comparados aos investimentos necessários aos sistemas de transporte coletivo de massa propostos com caráter complementar, apesar das significativas diferenças dos volumes de passageiros potencialmente atendidos por cada sistema.

É inegável que ambos definiram o quadro referencial para o enfrentamento dos problemas de mobilidade urbana nas duas maiores metrópoles brasileiras na segunda metade do século XX, especialmente 0 protagonismo da expansão do sistema rodoviário frente à ampliação e qualificação das redes de transporte coletivo sobre trilhos. Em São Paulo, ainda que o modelo de rede em grelha não tenha suplantado o esquema viário radioconcêntrico, os investimentos públicos para a circulação na cidade se concentraram na criação de avenidas dotadas pontualmente dos dispositivos típicos das inviáveis vias expressas propostas pelo PUB, como tuneis e viadutos, com diversos efeitos negativos nos tecidos urbanos impactados. Já no Rio de Janeiro, a execução de algumas propostas de vias expressas do Plano Doxiadis revela uma influência persistente na definição do modelo de intervenção urbana para a mobilidade, ainda que recentemente acrescida de iniciativas para qualificação do transporte coletivo por BRT.

Nos dois Planos analisados as ferramentas computacionais para simulação e avaliação da eficiência de alternativas de redes de transporte e de desenvolvimento urbano foram utilizadas e apresentadas como trunfos do moderno processo de planejamento executado, mesmo com as limitações de dados disponíveis no Estado da Guanabara e com os resultados frustrados no caso do PUB. Tais ferramentas, desenvolvidas no exterior e adaptadas o tanto quanto possível à realidade local pela contratação de serviços de consultorias privadas internacionais, vieram acompanhadas de outras práticas de planejamento, como índices para variados cálculos de demanda, densidades populacionais ideais, conceitos urbanísticos e das ideias de zoneamento.

Se o discurso estava descolado da realidade, as novas práticas de planejamento adotadas nos dois planos tiveram que ser acompanhadas de representações, e ambos apresentam suas verdades por meio de signos que provam uma realidade ausente: mapas que ilustram propostas e esquemas ideais (impossíveis de serem implantados por diversos motivos), exemplos de best practices (advindos de contextos totalmente diversos), modelos matemáticos, tabelas com cálculos extensos e resultados de processamentos eletrônicos (efetuados com dados insuficientes ou que provaram a inadequação das propostas finais). Trata-se da deturpação da representação de práticas consideradas legítimas para conferir respeito e submissão (Chartier, 1988) ao planejamento urbano tecnocrata.

Esses modelos de abordagem de planejamento consolidaram determinados enfoques das questões urbanas que permanecem na atividade atual da disciplina em São Paulo: o uso de técnicas estrangeiras para propor intervenções locais sem avaliação crítica, a resistência em incorporar a participação popular, a ênfase nas grandes estruturas e ideias sem compromisso com seu rebatimento em escala local ou viabilidade de implantação, e a ideologia de que a resolução dos problemas urbanos relaciona-se mais à ausência de planejamento do que aos condicionantes advindos da própria organização da sociedade. 
Nesse sentido, é como se a atividade de planejamento e do urbanismo, que como disciplinas surgiram para lidar com os impactos da industrialização no espaço, tivesse como uma de suas funções a ocultação das causas reais dos problemas urbanos e ainda representasse uma pretensa pró-atividade do Estado. Assim, ao fazer planos, é como se os governos pudessem justificar sua existência mesmo que inativa ou insuficiente no enfrentamento das questões urbanas, pois os resultados dos estudos mostram-se, invariavelmente, com extensas propostas inviáveis de serem implantadas. De fato, os planos oferecem projetos para toda a cidade, mas somente alguns são eleitos para serem executados - provavelmente aqueles que auxiliem mais diretamente ou de maneira mais evidenciada na reprodução do modo de produção ou se alinhem aos interesses dos dominantes. Os que ficam de lado são justificados pela ausência de recursos financeiros ou problemas ambientais.

Assim, é possível especular que a ênfase recente no planejamento da mobilidade urbana no Brasil (especialmente a partir da promulgação da Política Nacional de Mobilidade Urbana - Lei 12.587/2012) seja somente uma reação à percepção que o discurso de planejamento precisava ser repaginado para manter a crença no planejamento urbano como o que falta para melhorar a vida nas cidades e seguir mantendo as verdadeiras origens dos problemas. De qualquer forma, percebe-se assim que a compreensão da construção conceitual e técnica do planejamento urbano, e da mobilidade como participante desse discurso em cada período, são reveladoras tanto das questões urbanas quanto das sociedades que as enfrentam.

\section{BIBLIOGRAFIA}

CHARTIER, R. (1988). A história cultural entre práticas e representações. Trad. Maria Manuela Galhardo. Lisboa: Difusão Editorial.

CHARTIER, R. (2009). As práticas da escrita. In: CHARTIER, R. (Org.), História da vida privada: da Renascença ao Século das Luzes. (113-162). São Paulo: Companhia da Letras.

DOXIADIS ASSOCIATES. (1965). Guanabara. A Plan for Urban Development. Rio de Janeiro: CEDUG.

FELDMAN, S. (2005). Planejamento e Zoneamento. São Paulo: 1947 - 1972. São Paulo: Editora da Universidade de São Paulo/Fapesp.

GRILLO, M. T. O. (2013). A estratégia por trás do estratégico: dos planos de desenvolvimento aos planos estratégicos. Tese (Doutorado em Planejamento Urbano e Regional) - Faculdade de Arquitetura e Urbanismo, Universidade de São Paulo.

MIRANDA, T. C. R. (1989). A história cultural entre práticas e representações. Revista de História (São Paulo), $121,149-154$.

REZENDE, V. L. F. M. (2016). Planos, Regulação Urbanística e Intervenções Urbanas no Rio de Janeiro: Diferenças entre Pensar e Produzir a Cidade. Cadernos de Pós-Graduação em Arquitetura e Urbanismo (São Paulo), 15/1, 59-81.

RODRÍGUEZ SOSA, M. (2008). A Guanabara de Doxiadis e a Havana de Sert. Ekistics e Urban Design, novas direções na ruptura do CIAM. Tese (Doutorado em Urbanismo). PROURB-FAU/UFRJ.

SÃo PAULO, Prefeitura. (1969). Plano Urbanístico Básico. São Paulo: PMSP.

SOMEKH, N.; CAMPOS NETO, C. M. (2002). O Super-Plano: PUB-Plano Urbanístico Básico. In: SOMEKH, N.; CAMPOS, C. M. (Org.), A cidade que não pode parar - Planos urbanísticos de São Paulo no século XX (109-120). São Paulo: Editora Mackpesquisa.

VILLAÇA, F. (1999). Uma contribuição para a história do planejamento urbano no Brasil. In DEÁK, C.; SCHIFFER, S. R. (Orgs.), O processo de urbanização no Brasil (169-259). São Paulo: Fupam, Edusp. 